\title{
Increased Detection of Colorectal Polyps in Screening Colonoscopy Using High Definition i-SCAN Compared with Standard White Light
}

\author{
Woo Jung Kim, Sang Young Park, Iksoo Park, Wook Jin Lee, Jaechan Park, Nuri Chon, Tak Geun Oh and Kwang Hyun Kim \\ Division of Gastroenterology and Hepatology, Department of Internal Medicine, Hallym Hospital, Incheon, Korea
}

Background/Aims: The aim of this study was to evaluate the efficacy of high definition (HD) i-SCAN for colorectal polyp detection in screening colonoscopy.

Methods: We retrospectively analyzed the records of 501 patients who had undergone screening colonoscopy performed by three endoscopists with either HD i-SCAN ( $n=149)$ or standard white light $(n=352)$ from January 2, 2014 through June 30, 2014. Patient information and inter-endoscopist variation as well as polyp number, endoscopic findings, and pathologic characteristics were reviewed.

Results: The detection rates of colorectal and neoplastic polyps were significantly higher using HD i-SCAN than standard white light colonoscopy ( $52 \%$ vs. $38.1 \%$, $p=0.004$ for colorectal polyps; and $37.2 \%$ vs. $27.9 \%, p=0.041$ for neoplastic polyps). Analysis of endoscopic findings revealed no difference in detected polyp size between HD i-SCAN and standard white light colonoscopy (4.59 $\pm 2.35 \mathrm{~mm}$ vs. $4.82 \pm 2.81 \mathrm{~mm}, p=0.739$ ), but non-protruding polyps were more commonly detected by i-SCAN than by standard white light colonoscopy $(24.6 \%$ vs. $13.5 \%, p=0.007)$.

Conclusions: Colonoscopy using HD i-SCAN had a significantly higher detection rate of colorectal polyps, including neoplastic polyps, because of improved sensitivity for detecting non-protruding lesions. Clin Endosc 2016;49:69-75

Key Words: i-SCAN; Chromoendoscopy; Colonic polyps; Colonoscopy

\section{INTRODUCTION}

Colonoscopy is considered the optimal examination method for detecting colorectal polyps, particularly in view of the ability to provide therapeutic polypectomy in conjunction with diagnosis. However, colonoscopy is not perfect. The rate of interval cancer is $3 \%$ to $6 \%{ }^{1,2}$ which has been inversely linked to adenoma detection rates using screening colonoscopy. ${ }^{3}$ Indeed, colonoscopic miss rates range from $6 \%$ to $12 \%$ for adenomas larger than $1 \mathrm{~cm}$.

Received: January 14, 2015 Revised: March 16, 2015

Accepted: May 1, 2015

Correspondence: Kwang Hyun Kim

Division of Gastroenterology and Hepatology, Department of Internal Medicine, Hallym Hospital, 722, Jangje-ro, Gyeyang-gu, Incheon 21079, Korea

Tel: +82-32-540-9114, Fax: +82-32-545-1844, E-mail: kaizersoze77@naver.com

Woo Jung Kim and Sang Young Park contributed equally to this work as first authors.

(c) This is an Open Access article distributed under the terms of the Creative Commons Attribution Non-Commercial License (http://creativecommons.org/ licenses/by-nc/3.0) which permits unrestricted non-commercial use, distribution, and reproduction in any medium, provided the original work is properly cited.
As concerns increase about the effectiveness of colonoscopy for detection of adenomas and early-stage colorectal cancer, new endoscopic techniques have been introduced. Chromoendoscopy and cap-assisted colonoscopy show benefits over standard colonoscopy for colorectal polyp detection. ${ }^{6,7}$ However, these methods are not suitable for all colonoscopy cases. Chromoendoscopy is inconvenient due to the need for dye spraying and the suction of collected dye in the colon, and cap-assisted colonoscopy requires extra equipment to be added onto standard colonoscopes. Other technologies such as capsule colonoscopy, magnification endoscopy, and confocal laser endomicroscopy have been used to increase detection of colorectal polyps, but their value in screening has yet to be determined. ${ }^{8,9}$

Virtual chromoendoscopy, including narrow-band imaging (NBI; Olympus, Tokyo, Japan), Fujinon imaging color enhancement (FICE; Fujinon, Tokyo, Japan), and i-SCAN (Pentax, Tokyo, Japan) are used for detecting and characterizing subtle epithelial lesions in the gastrointestinal tract. ${ }^{10}$ These virtual chromoendoscopes are equipped with a push-button 
system that enables rapid switching between white light (WL) images and computer-enhanced images. They have shown promising efficacy for predicting the real-time histology of epithelial lesions. ${ }^{10,11}$ However, most of the studies using NBI or FICE did not show a significant improvement in detection of colorectal polyps. ${ }^{12-15}$

The efficacy of colorectal polyp detection using i-SCAN has not been established since there have been very few studies. $^{16-20}$ The aim of this study was to determine the usefulness of i-SCAN for the detection of colorectal polyps via a comparison of colonoscopy using high definition (HD) i-SCAN to standard WL colonoscopy.

\section{MATERIALS AND METHODS}

\section{Study population and data collection}

The present study was performed on 1,957 persons who received colonoscopy during medical checkups at the Health Promotion Center of Hallym Hospital between January 2, 2014 and June 30, 2014. A total of 501 cases were defined as screening colonoscopy using the following inclusion criteria: (1) age 40 to 75 years; (2) no history of gastrointestinal signs, symptoms, and/or relevant diagnoses; (3) no history of colon cancer, polyps, and/or gastrointestinal disease; (4) no family history of colorectal cancer; and (5) no history of colorectal examination, including sigmoidoscopy, colonoscopy, and barium enema, within the previous 5 years. All colonoscopies were performed by three experienced endoscopists certified by the Korean Society of Gastrointestinal Endoscopy.

The data were analyzed retrospectively using electronic medical records, colonoscopy reports and images, and pathology reports. Colonoscopy reports included the name of the endoscopists; the type of instruments; whether or not it was a complete colonoscopy; intubation and withdrawal time; bowel preparation quality; endoscopic characteristics of detected colorectal polyps, including number, size, location, and morphology according to the Paris classification; ${ }^{21}$ and polyp removal method. In reviewing the characteristics of detected colorectal polyps, we simultaneously investigated endoscopic images and colonoscopy and pathology reports to identify whether polyps were detected during the intubation period. Polyps or cancers detected during the intubation period were excluded from the analysis. The polyp detection rate was defined as the proportion of patients with at least one polyp.

In additional reviews of endoscopic and pathologic findings, all detected polyps were analyzed. Endoscopic morphologies of colorectal polyps were separated into protruding lesions, including sessile, semi-pedunculated and pedunculated, and non-protruding lesions. Neoplastic polyps were defined as low-grade dysplasia, high-grade dysplasia, tubulovillous, serrated adenoma, and carcinoma in situ.

The study was approved by the Institutional Review Board at Hallym Hospital.

\section{Colonoscopy equipment}

HD i-SCAN colonoscopies were performed with EPK-i5000 (Pentax EPKi processor) and EC38-i10F model colonoscopes (Pentax). The i-SCAN has three distinct modes of image enhancement. Surface enhancement (SE) highlights structure through recognition of the edges, and contrast enhancement (CE) highlights depressions and structural differences through colored presentation of low-density areas. Tone enhancement (TE), similar to NBI, dissects and analyzes the individual red, green, and blue components of an ordinary endoscopic image and enhances the image by recombining altered color frequencies. ${ }^{22}$ The i-SCAN can be used in a single mode or combined modes. SE and CE each have three enhancement levels $(2+, 3+$, and $4+)$, and TE has six modes for pit pattern, vessel, Barrett's, esophagus, stomach, and colorectum. Since increased enhancement using SE and CE modes results in heightened endoscopic imaging noise, settings needed to be optimized for general application. After a 2-month introductory period in our hospital, we decided that the optimal i-SCAN mode settings for colorectal polyp detection were $2+$ for SE, $2+$ for $\mathrm{CE}$, and colorectum mode for TE. When HD i-SCAN was used, the colonoscope was inserted into the cecum base in the $\mathrm{WL}$ mode. The withdrawal phase was then performed using the i-SCAN mode.

Standard WL colonoscopies were performed with an EVIS LUCERA CV-260 processor, EVIS LUCERA CLV-260 light source, and CF type H260AL/I colonoscopes (Olympus).

\section{Colonoscopy procedure}

Three endoscopy units are available for patients undergoing screening colonoscopy in the Health Promotion Center. Two are equipped with standard WL colonoscopy settings and one with HD i-SCAN colonoscopy settings. Three endoscopists regularly rotated through the two endoscopic techniques depending on availability of the instruments.

All patients received standard bowel preparation, which included 2 L of polyethylene glycol (Coolprep powder; Taejun, Seoul, Korea) and $2 \mathrm{~L}$ of free water at home. Bowel preparation quality was assessed using the Aronchick bowel preparation scale. ${ }^{23}$ The three endoscopists followed the rules of the Hallym endoscopy unit as follows: (1) the minimal withdrawal time was at least 6 minutes; (2) endoscopists intubated the cecum quickly and confirmed cecal intubation by documenting a cecal landmark such as the cecal valve or appendix orifice; (3) the size of all polyps was measured by open biopsy forceps; 
and (4) all detected polyps were directly removed during the procedure using biopsy or polypectomy.

\section{Statistical analysis}

All analyses were performed using SPSS version 17.0 (SPSS Inc., Chicago, IL, USA). The chi-square test or Fisher exact test were performed for categorical variables. Quantitative data were summarized using mean values and standard deviations (SD), and the Mann-Whitney test was performed to detect significant differences. A $p<0.05$ indicated a significant difference.

\section{RESULTS}

\section{Baseline characteristics and colonoscopy quality as- sessment}

Base line characteristics of the study population and colonoscopy quality indicators are summarized in Table 1. A total of 501 colonoscopies were evaluated (HD i-SCAN, $n=149$; standard WL, $n=352$ ). Nine cases were excluded due to poor bowel preparation (HD i-SCAN, $n=1$; standard WL, $n=8$ ). The study population was predominantly male (56.3\%) and the mean \pm SD was $51.2 \pm 11.73$ years. There was no significant difference in sex, age, or bowel preparation between the two groups. The withdrawal time (mean $\pm \mathrm{SD}$, range) was longer using HD i-SCAN (7.18 \pm 2.54 minutes [range, 6 to 30]) than standard WL colonoscopy (6.80 \pm 1.75 minutes [range, 6 to 25 ]; $p=0.007$ ). However, in further analysis of the withdrawal time according to whether colon polyps were detected or not, there were no significant differences between the two groups.

Three endoscopists performed 189, 141, and 162 colonoscopies, respectively. There was no significant difference between the proportion of times each used HD i-SCAN (31.7\%, 30.5\%, and $27.8 \%$ of the time, respectively, $p=0.716$ ). Polyp detection rates were $43.9 \%$ vs. $38.3 \%$ vs. $43.3 \%$ ( $p=0.527$ ) for colorectal polyps, and $30.7 \%$ vs. $28.4 \%$ vs. $32.7 \%$ ( $p=0.715$ ) for neoplastic polyps, respectively. There were no significant differences between the three endoscopists (Table 2).

\section{Colorectal polyp and neoplastic polyp detection rate} HD i-SCAN colonoscopy showed that 77 of the 148 subjects had colorectal polyps and that 55 of the 77 patients with polyps had at least one neoplastic polyp. Polyp detection rates were significantly higher using HD i-SCAN than standard WL colonoscopy ( $52 \%$ vs. $38.1 \%, p=0.004$ for overall colorectal polyps detected; $37.2 \%$ vs. $27.9 \%, p=0.041$ for neoplastic polyps detected) (Table 3 ). A total of 363 polyps were identified during the withdrawal phase. HD i-SCAN and standard WL colonoscopy detected 134 and 229 polyps, respectively. A

Table 1. Baseline Characteristics and Colonoscopy Quality Assessment

\begin{tabular}{lccc}
\hline Characteristic & HD i-SCAN $(\boldsymbol{n = 1 4 8})$ & Standard WL $(\boldsymbol{n}=\mathbf{3 4 4})$ & $\boldsymbol{p}$-value \\
\hline Age, yr & $51.61 \pm 12.27$ & $51.07 \pm 11.50$ & 0.995 \\
Male sex & $90(60.8)$ & $187(54.4)$ & 0.186 \\
Withdrawal time, min & & & \\
$\quad$ Overall & $7.18 \pm 2.54(6-30)$ & $6.80 \pm 1.75(6-25)$ & 0.007 \\
$\quad$ Polyp detection & $8.18 \pm 3.20(6-30)$ & $8.02 \pm 2.37(6-25)$ & 0.896 \\
$\quad$ Not polyp detection & $6.10 \pm 0.35(6-8)$ & $6.05 \pm 0.21(6-7)$ & 0.227 \\
Bowel preparation & & & 0.450 \\
Excellent & $60(40.5)$ & $123(35.1)$ & $172(50.0)$ \\
Good & $72(48.6)$ & $49(14.2)$ & \\
Fair & $16(10.8)$ & & \\
\hline
\end{tabular}

Values are presented as mean $\pm \mathrm{SD}$, number (\%), or mean $\pm \mathrm{SD}$ (range).

HD, high definition; WL, white light.

Table 2. Interendoscopist Variation

\begin{tabular}{lcccc} 
Variable & $\begin{array}{c}\text { Endoscopist 1 } \\
(\boldsymbol{n}=\mathbf{1 8 9})\end{array}$ & $\begin{array}{c}\text { Endoscopist 2 } \\
(\boldsymbol{n}=\mathbf{1 4 1})\end{array}$ & $\begin{array}{c}\text { Endoscopist 3 } \\
(\boldsymbol{n}=\mathbf{1 6 2})\end{array}$ & p-value \\
\hline Rates of i-SCAN use & $60(31.7)$ & $43(30.5)$ & $45(27.8)$ & 0.716 \\
Colorectal polyp detection & $83(43.9)$ & $54(38.3)$ & $71(43.3)$ & 0.527 \\
Neoplastic polyp detection & $58(30.7)$ & $40(28.4)$ & $53(32.7)$ & 0.715 \\
\hline
\end{tabular}

Values are presented as number (\%). 
Table 3. Colorectal and Neoplastic Polyp Detection Rate

\begin{tabular}{lccc}
\hline Characteristic & HD i-SCAN $(\boldsymbol{n = 1 4 8})$ & Standard WL $(\boldsymbol{n}=\mathbf{3 4 4})$ & $\boldsymbol{p}$-value \\
\hline Colorectal polyp & $77(52)$ & $131(38.1)$ & 0.004 \\
Neoplastic polyp & $55(37.2)$ & $96(27.9)$ & 0.041 \\
Mean colorectal polyp & $0.96 \pm 1.38$ & $0.71 \pm 1.26$ & 0.005 \\
Mean neoplastic polyp & $0.66 \pm 1.24$ & $0.50 \pm 1.08$ & 0.044 \\
\hline
\end{tabular}

Values are presented as number (\%) or mean \pm SD.

HD, high definition; WL, white light.

Table 4. Characteristics of Endoscopic and Pathologic Findings of Identified Colorectal Polyps

\begin{tabular}{|c|c|c|c|}
\hline Characteristic & HD i-SCAN $(n=134)$ & Standard WL $(n=229)$ & $p$-value \\
\hline Size, $\mathrm{mm}$ & $4.59 \pm 2.35$ & $4.82 \pm 2.81$ & 0.739 \\
\hline Morphology & & & 0.007 \\
\hline Protruding & $101(75.4)$ & $198(86.5)$ & \\
\hline Non-protruding & $33(24.6)$ & $31(13.5)$ & \\
\hline Location & & & 0.472 \\
\hline Right side & $59(44.0)$ & $92(40.2)$ & \\
\hline Left side & $75(56.0)$ & $137(59.8)$ & \\
\hline Pathology & & & 0.351 \\
\hline Low grade dysplasia & $82(61.2)$ & $138(60.3)$ & \\
\hline High grade dysplasia & 0 & $4(1.7)$ & \\
\hline Tubulovillous adenoma & $3(2.2)$ & $10(4.4)$ & \\
\hline Serrated adenoma & $8(6)$ & $7(3.1)$ & \\
\hline Hyperplastic & $14(10.4)$ & $30(13.1)$ & \\
\hline Carcinoma in situ & 0 & $1(0.4)$ & \\
\hline Others $^{\mathrm{a})}$ & $27(20)$ & $39(20.1)$ & \\
\hline Neoplastic vs. non & & & 0.926 \\
\hline Neoplastic polyp & $93(69.4)$ & $160(69.9)$ & \\
\hline Non-neoplastic polyp & $41(30.6)$ & $69(30.1)$ & \\
\hline
\end{tabular}

Values are presented as mean \pm SD or number (\%).

$\mathrm{HD}$, high definition; WL, white light.

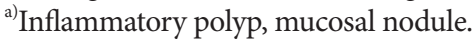

significantly higher mean number of colorectal and neoplastic polyps were detected by HD i-SCAN than standard WL colonoscopy ( $0.96 \pm 1.38$ vs. $0.71 \pm 1.26, p=0.005$ for colorectal polyps; $0.66 \pm 1.24$ vs. $0.50 \pm 1.08, p=0.044$ for neoplastic polyps).

\section{Characteristics of endoscopic and pathologic find- ings of identified colorectal polyps}

Table 4 shows the detailed endoscopic and pathologic characteristics of the detected polyps. The mean polyp sizes $( \pm S D)$ using HD i-SCAN and standard WL colonoscopy did not show significant differences $(4.59 \pm 2.35 \mathrm{~mm}$ vs. $4.82 \pm 2.81$ $\mathrm{mm}, p=0.739$ ). However, non-protruding polyps were more commonly detected by HD i-SCAN than by standard WL colonoscopy ( $24.6 \%$ vs. $13.5 \%, p=0.007)$. There was no sig- nificant difference in colorectal polyp location between the two groups. Pathologic findings showed that the proportion of neoplastic polyps detected was not different between $\mathrm{HD}$ i-SCAN and standard WL colonoscopy ( $69.4 \%$ vs. $69.9 \%$, $p=0.926$ ).

\section{DISCUSSION}

Virtual chromoendoscopies have been proposed to lead to better recognition of small or flat lesions, but the absolute increase in diagnostic yield seems limited. NBI, one of the most widely used and extensively studied image enhancement technologies, did not show a clear benefit for the detection of 
Table 5. Summary of Five Studies Evaluating the Efficacy of HD i-SCAN for Colorectal Polyp Detection

\begin{tabular}{|c|c|c|c|c|c|c|c|}
\hline Study & $\begin{array}{c}\text { No. of } \\
\text { patients }\end{array}$ & Design & $\begin{array}{c}\text { Study } \\
\text { population }\end{array}$ & Detail of intervention & $\begin{array}{c}\text { Control } \\
\text { group }\end{array}$ & $\begin{array}{c}\text { Efficacy for } \\
\text { polyp detection }\end{array}$ & Note \\
\hline $\begin{array}{l}\text { Hoffman et al. } \\
(2010)^{16}\end{array}$ & 220 & $\begin{array}{l}\text { Prospective, } \\
\text { randomized, } \\
\text { controlled }\end{array}$ & $\begin{array}{l}\text { Screening } \\
\text { Surveillance }\end{array}$ & HD i-SCAN (SE) & $\begin{array}{l}\text { Standard } \\
\text { WL }\end{array}$ & Positive & $\begin{array}{l}\text { Full } \\
\text { colonoscopy }\end{array}$ \\
\hline $\begin{array}{l}\text { Hoffman et al. } \\
\qquad(2010)^{17}\end{array}$ & 69 & $\begin{array}{l}\text { Prospective } \\
\text { randomized }\end{array}$ & Screening & $\begin{array}{l}\text { HD i-SCAN (SE), } \\
\text { chromoendoscopy } \\
\text { (methylene blue) }\end{array}$ & HD WL & Positive & $\begin{array}{l}\text { Last } 30 \mathrm{~cm} \text { of } \\
\text { the colon }\end{array}$ \\
\hline $\begin{array}{l}\text { Testoni et al. } \\
(2012)^{18}\end{array}$ & 1,101 & Retrospective & $\begin{array}{l}\text { Screening } \\
\text { Diagnostic } \\
\text { Surveillance }\end{array}$ & $\begin{array}{l}\text { HD i-SCAN } \\
\quad(\mathrm{SE} / \mathrm{CE} / \mathrm{TE})\end{array}$ & $\begin{array}{l}\text { Standard } \\
\text { WL }\end{array}$ & Positive & $\begin{array}{l}\text { Full } \\
\text { colonoscopy }\end{array}$ \\
\hline $\begin{array}{l}\text { Hong et al. } \\
(2012)^{19}\end{array}$ & 389 & $\begin{array}{l}\text { Prospective, } \\
\text { randomized, } \\
\text { back-to-back }\end{array}$ & Screening & $\begin{array}{l}\text { HD i-SCAN (SE/CE) } \\
\text { HD i-SCAN (SE/CE/TE) }\end{array}$ & HD WL & Negative & $\begin{array}{l}\text { Full } \\
\text { colonoscopy }\end{array}$ \\
\hline $\begin{array}{l}\text { Hoffman et al. } \\
\qquad(2014)^{20}\end{array}$ & 80 & $\begin{array}{l}\text { Prospective, } \\
\text { randomized, } \\
\text { tandem }\end{array}$ & $\begin{array}{l}\text { Screening } \\
\text { Surveillance }\end{array}$ & HD i-SCAN (TE) & HD WL & Positive & $\begin{array}{l}\text { Full } \\
\text { colonoscopy }\end{array}$ \\
\hline
\end{tabular}

HD, high definition; SE, surface enhancement; WL, white light; CE, contrast enhancement; TE, tone enhancement.

colorectal polyps compared with standard or HD WL colonoscopy ${ }^{12,13,24}$ In contrast, NBI is useful for detecting lesions in small lumens, such as the esophagus. ${ }^{25,26}$ This difference might be caused by the fact that NBI images are much darker than WL images, particularly in regions like the colon and rectum that have a large luminal diameter. In contrast, i-SCAN is as bright as standard WL and could therefore be utilized for observing much larger areas than NBI and for improved detection of colorectal polyps. ${ }^{22}$ However, the effectiveness of i-SCAN for colorectal polyp detection is not yet clear because of insufficient data.

To date, only five studies have been published evaluating the efficacy of i-SCAN for colorectal polyp detection (Table 5). The heterogeneous methods used in these studies made it difficult to confirm the efficacy of i-SCAN for colorectal polyp detection. For this reason, additional data collection and studies are required.

The present study, even though retrospective, utilized a relatively large number of patients who underwent screening colonoscopies. In the present study, HD i-SCAN was significantly better at detecting colorectal and neoplastic polyps compared with standard WL colonoscopy. However, based on pathologic characteristics, the proportion of neoplastic polyps detected using HD i-SCAN vs. standard WL was nearly the same. Analysis of endoscopic characteristics of the detected polyps revealed that HD i-SCAN had a higher sensitivity of detecting non-protruding polyps. Therefore, it was suspected that the improved neoplastic polyp detection rate of $\mathrm{HD}$ i-SCAN resulted from its increased ability to detect non-protruding polyps, leading to an overall higher detection rate for all colorectal polyps, including neoplastic, hyperplastic, and inflammatory polyps. Colorectal polyp morphology, especially flat lesions, is a major factor influencing missed detection of polyps. ${ }^{27}$ In agreement with the present study, previous studies revealed the effectiveness of HD i-SCAN for detecting non-protruding lesions.

Other factors that influence colorectal polyps remaining undetected are poor colon cleansing, ${ }^{28}$ experience level of the endoscopist, and longer withdrawal time. ${ }^{29}$ In the present study, we took into account the differences in bowel preparation quality, withdrawal time, and interendoscopist variation including colorectal and neoplastic polyp detection rate, and usage rate between HD i-SCAN and standard WL colonoscopy. Although the withdrawal time for the HD i-SCAN was longer than for standard WL colonoscopy, this included the time it took to complete procedures, such as biopsies and polypectomies. Since more colorectal polyps were detected using HD i-SCAN, more time was required to remove polyps than with standard WL colonoscopy. If we had spent more time detecting colon polyps with HD i-SCAN than with standard WL colonoscopy, the withdrawal time might be longer, even when we did not detect polyps. However, when patients were grouped according to whether colon polyps were detected, further analysis of the withdrawal time (regardless of polyp detection) did not show a difference between HD i-SCAN and standard WL colonoscopy. These results indicated that the difference in withdrawal time resulted from procedure time relative to polyp detection, rather than an allowance of extra time specifically for HD i-SCAN colonoscopy.

Adenoma detection rate is an important measure of high-quality endoscopy. An older version of the guideline suggests adenoma detection rates of at least $25 \%$ for men and 
$15 \%$ for women at average risk, ${ }^{30}$ and a more recent study reported adenoma detection rates of $33.7 \% .^{31}$ A simple comparison should not be made between adenoma detection rates of previous studies and the neoplastic polyp detection rate of the present study; with respect to neoplastic polyps, including adenomas and carcinoma in situ, which were detected only during withdrawal, the neoplastic polyp detection rates of $\mathrm{HD}$ i-SCAN and standard WL colonoscopy were similar or higher than in a previous study.

New imaging technology, including i-SCAN, can permit the endoscopist to be more focused during procedures than usual, and will probably promote greater accuracy in polyp detection; however, there is a significant learning curve for its use, even by an expert. To eliminate this bias, we used a 2-month introductory period to identify an optimal i-SCAN mode setting, and the three endoscopists respectively performed 111, 95, and 87 procedures with HD i-SCAN during the introductory period, including screening, surveillance, and diagnostic colonoscopy.

It is possible that HD imaging quality influenced the polyp detection rate independently of i-SCAN usage. Although HD colonoscopy provides better imaging, it is not clear that $\mathrm{HD}$ colonoscopy is a better diagnostic tool for colorectal polyp detection. There is some evidence that HD colonoscopy combined with virtual chromoendoscopy, especially NBI, improved detection of colorectal polyps compared with standard WL colonoscopy alone, ${ }^{32,33}$ but the majority of the studies evaluating polyp detection using HD compared to standard WL colonoscopies did not show increased efficacy. ${ }^{34,35}$ In the present study, we could not exclude the possibility that $\mathrm{HD}$ added value to the i-SCAN compared to standard WL colonoscopy. A prospective, large-scale study is needed to further characterize the usefulness of HD i-SCAN chromoendoscopy.

In conclusion, our study showed that HD i-SCAN, a newly developed, virtual chromoendoscopy technique, improved detection of colorectal polyps in screening colonoscopy via increased sensitivity for non-protruding polyps. We suggest that increased use of HD i-SCAN chromoendoscopy in clinical practice could lead to more neoplastic polyp detection.

\section{Conflicts of Interest}

The authors have no financial conflicts of interest.

\section{REFERENCES}

1. Hosokawa O, Shirasaki S, Kaizaki Y, Hayashi H, Douden K, Hattori M. Invasive colorectal cancer detected up to 3 years after a colonoscopy negative for cancer. Endoscopy 2003;35:506-510.

2. Farrar WD, Sawhney MS, Nelson DB, Lederle FA, Bond JH. Colorectal cancers found after a complete colonoscopy. Clin Gastroenterol Hepatol 2006;4:1259-1264.
3. Kaminski MF, Regula J, Kraszewska E, et al. Quality indicators for colonoscopy and the risk of interval cancer. N Engl J Med 2010;362:17951803.

4. Rex DK, Cutler CS, Lemmel GT, et al. Colonoscopic miss rates of adenomas determined by back-to-back colonoscopies. Gastroenterology 1997;112:24-28.

5. Pickhardt PJ, Nugent PA, Mysliwiec PA, Choi JR, Schindler WR. Location of adenomas missed by optical colonoscopy. Ann Intern Med 2004;141:352-359.

6. Kiesslich R, von Bergh M, Hahn M, Hermann G, Jung M. Chromoendoscopy with indigocarmine improves the detection of adenomatous and nonadenomatous lesions in the colon. Endoscopy 2001;33:10011006.

7. Ng SC, Tsoi KK, Hirai HW, et al. The efficacy of cap-assisted colonoscopy in polyp detection and cecal intubation: a meta-analysis of randomized controlled trials. Am J Gastroenterol 2012;107:1165-1173.

8. Riccioni ME, Urgesi R, Cianci R, Bizzotto A, Spada C, Costamagna G. Colon capsule endoscopy: advantages, limitations and expectations. Which novelties? World J Gastrointest Endosc 2012;4:99-107.

9. Wallace MB, Kiesslich R. Advances in endoscopic imaging of colorectal neoplasia. Gastroenterology 2010;138:2140-2150.

10. Cho WY, Jang JY, Lee DH; Endoscopic Technology and Investigation Study Group. Recent advances in image-enhanced endoscopy. Clin Endosc 2011;44:65-75.

11. Koo JS. Equipment-based image-enhanced endoscopy for differentiating colorectal polyps. Clin Endosc 2014;47:330-333.

12. Dinesen L, Chua TJ, Kaffes AJ. Meta-analysis of narrow-band imaging versus conventional colonoscopy for adenoma detection. Gastrointest Endosc 2012;75:604-611.

13. Adler A, Aschenbeck J, Yenerim T, et al. Narrow-band versus white-light high definition television endoscopic imaging for screening colonoscopy: a prospective randomized trial. Gastroenterology 2009;136:410-416. el.

14. Chung SJ, Kim D, Song JH, et al. Efficacy of computed virtual chromoendoscopy on colorectal cancer screening: a prospective, randomized, back-to-back trial of Fuji Intelligent Color Enhancement versus conventional colonoscopy to compare adenoma miss rates. Gastrointest Endosc 2010;72:136-142.

15. Aminalai A, Rösch T, Aschenbeck J, et al. Live image processing does not increase adenoma detection rate during colonoscopy: a randomized comparison between FICE and conventional imaging (Berlin Colonoscopy Project 5, BECOP-5). Am J Gastroenterol 2010;105:2383-2388.

16. Hoffman A, Sar F, Goetz M, et al. High definition colonoscopy combined with i-Scan is superior in the detection of colorectal neoplasias compared with standard video colonoscopy: a prospective randomized controlled trial. Endoscopy 2010;42:827-833.

17. Hoffman A, Kagel C, Goetz M, et al. Recognition and characterization of small colonic neoplasia with high-definition colonoscopy using i-Scan is as precise as chromoendoscopy. Dig Liver Dis 2010;42:45-50.

18. Testoni PA, Notaristefano C, Vailati C, Di Leo M, Viale E. High-definition colonoscopy with i-Scan: better diagnosis for small polyps and flat adenomas. World J Gastroenterol 2012;18:5231-5239.

19. Hong SN, Choe WH, Lee JH, et al. Prospective, randomized, back-toback trial evaluating the usefulness of i-SCAN in screening colonoscopy. Gastrointest Endosc 2012;75:1011-1021.e1.

20. Hoffman A, Loth L, Rey JW, et al. High definition plus colonoscopy combined with i-scan tone enhancement vs. high definition colonoscopy for colorectal neoplasia: a randomized trial. Dig Liver Dis 2014;46:991-996.

21. Participants in the Paris Workshop. The Paris endoscopic classification of superficial neoplastic lesions: esophagus, stomach, and colon: November 30 to December 1, 2002. Gastrointest Endosc 2003;58(6 Sup$\mathrm{pl}): S 3-S 43$.

22. Kodashima S, Fujishiro M. Novel image-enhanced endoscopy with i-scan technology. World J Gastroenterol 2010;16:1043-1049. 
23. Aronchick CA, Lipshutz WH, Wright SH, Dufrayne F, Bergman G. A novel tableted purgative for colonoscopic preparation: efficacy and safety comparisons with Colyte and Fleet Phospho-Soda. Gastrointest Endosc 2000;52:346-352.

24. Pasha SF, Leighton JA, Das A, et al. Comparison of the yield and miss rate of narrow band imaging and white light endoscopy in patients undergoing screening or surveillance colonoscopy: a meta-analysis. Am J Gastroenterol 2012;107:363-370.

25. Lee CT, Chang CY, Lee YC, et al. Narrow-band imaging with magnifying endoscopy for the screening of esophageal cancer in patients with primary head and neck cancers. Endoscopy 2010;42:613-619.

26. Lambert R. Endoscopic diagnosis of dysplasia in Barrett's esophagus. Expert Rev Gastroenterol Hepatol 2013;7:303-305.

27. Heresbach D, Barrioz T, Lapalus MG, et al. Miss rate for colorectal neoplastic polyps: a prospective multicenter study of back-to-back video colonoscopies. Endoscopy 2008;40:284-290.

28. Hong SN, Sung IK, Kim JH, et al. The effect of the bowel preparation status on the risk of missing polyp and adenoma during screening colonoscopy: a tandem colonoscopic study. Clin Endosc 2012;45:404-411.

29. Rex DK. Maximizing detection of adenomas and cancers during colonoscopy. Am J Gastroenterol 2006;101:2866-2877.
30. Fletcher RH, Nadel MR, Allen JI, et al. The quality of colonoscopy services: responsibilities of referring clinicians: a consensus statement of the Quality Assurance Task Group, National Colorectal Cancer Roundtable. J Gen Intern Med 2010;25:1230-1234.

31. Coe SG, Wallace MB. Assessment of adenoma detection rate benchmarks in women versus men. Gastrointest Endosc 2013;77:631-635.

32. Rastogi A, Early DS, Gupta N, et al. Randomized, controlled trial of standard-definition white-light, high-definition white-light, and narrow-band imaging colonoscopy for the detection of colon polyps and prediction of polyp histology. Gastrointest Endosc 2011;74:593-602.

33. Gross SA, Buchner AM, Crook JE, et al. A comparison of high definition-image enhanced colonoscopy and standard white-light colonoscopy for colorectal polyp detection. Endoscopy 2011;43:1045-1051.

34. Longcroft-Wheaton G, Brown J, Cowlishaw D, Higgins B, Bhandari P. High-definition vs. standard-definition colonoscopy in the characterization of small colonic polyps: results from a randomized trial. Endoscopy 2012;44:905-910.

35. Pellisé M, Fernández-Esparrach G, Cárdenas A, et al. Impact of wide-angle, high-definition endoscopy in the diagnosis of colorectal neoplasia: a randomized controlled trial. Gastroenterology 2008;135:1062-1068. 